\title{
Study on the Finance Supporting Policy of Technology-based Small and Micro Enterprises in Hebei
}

\author{
Siyun Xu, Shuoran Xiao \\ Hebei Finance University, Baoding, Hebei, 071051, China
}

Keywords: Technology-based Small and Micro Enterprises (SMEs); Financial Support; Models; the Game Theory

\begin{abstract}
This paper principally discusses a class of models for the relationship between small and micro enterprises and the local governments. The expressions of the financial policy, fund allocation based on fiscal expenditure efficiency, as well as the use of the funds supervised by the policies are derived in this paper, with the aim of increasing the efficiency of finance supporting for technology-based small and micro enterprises (SMEs) in Hebei through establishing carbon emission permits trade, advancing scientific and technical innovation, developing low-carbon economy and enhancing supervision of the government.
\end{abstract}

\section{Introduction}

In recent years, the low-carbon economy has increasingly become a hot issue among all nations across the world $[1,2]$. Thus, it is inevitable for all countries to develop low-carbon economy. Especially for our country, the progress of low-carbon economy represents not only the requirement of sustainable development, but also a vital means to realize the transformation of economic structure and industrial upgrading [3]. Technology-based small and micro enterprises are in unswerving pursuit of science and technology and benefits. As the most active organizations in scientific and technical innovation with enormous potential in economy, they are playing an increasingly important role in the national economy and social improvement. Over the past years, the economic condition in Hebei Province has been in great progress, with enterprise finance developing rapidly, technology-based enterprises growing at a high rate and the financial environment of science and technology promoting to some extent. Compared with Beijing and Tianjin, the two financial centers in the Beijing-Tianjin-Hebei metropolis circle, however, it still has a long way to go. Under the circumstance of economic integration of Beijing-Tianjin-Hebei metropolis circle, Hebei province, as an underdeveloped region next to Beijing and Tianjin, still has difficulties in developing its ecological environment of scientific and technological finance. In particular, many inhibiting factors are needed to be overcome in financing by financial institutions and services in intermediary agencies.

This paper principally studies the technology-based small and micro enterprises in Hebei. It presents the organic growth of low-carbon economy and financial policies. The approach requires the financial supporting model of technology-based small and micro enterprises in Hebei, and the models based on the game theory. The authors review that the government should appropriately adjust its financial policies to pay more attention to the development of low-carbon economy, so as to accelerate the transformation of economic growth and the structure upgrading.

\section{Technology-based small and micro enterprises in the low-carbon economy in Hebei face financial problems}

As showed in Figure 1, technology-based small and micro enterprises in the low-carbon economy in Hebei face some financial problems. Compared with large and medium enterprises, they have no competence in such aspects as management, technology and financing. In addition, they show their own unique features during growth. 


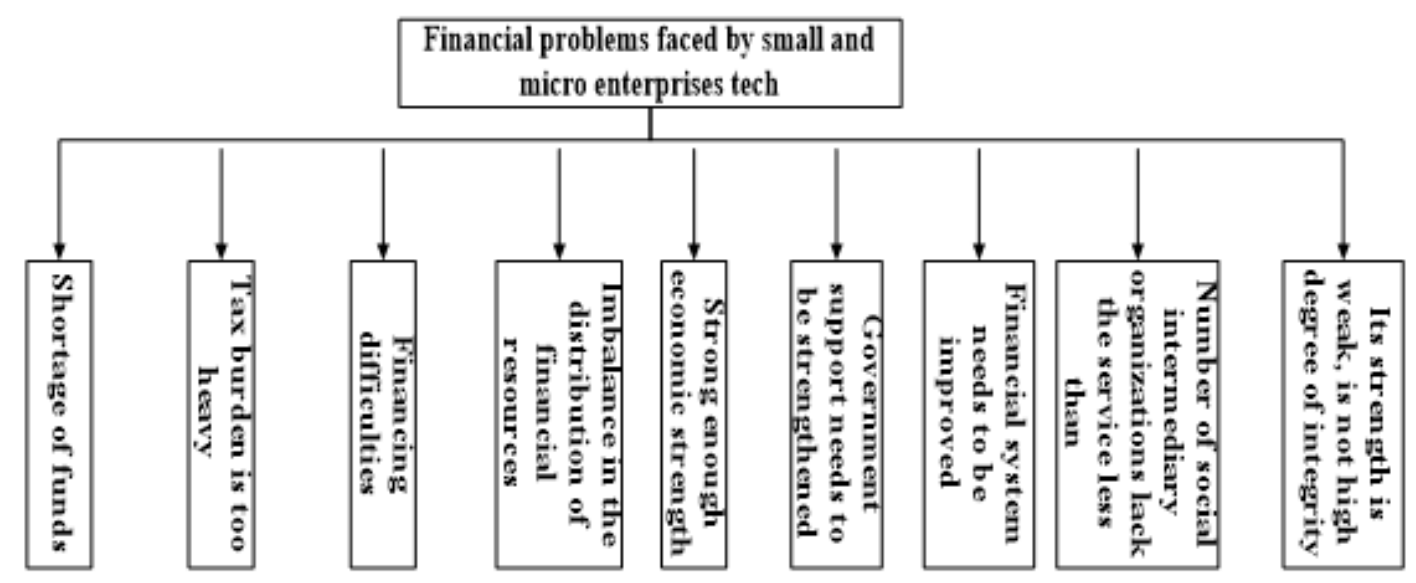

Figure 1 Financial problems faced by technology-based small and micro enterprises

(1) The economic power is not so strong. There is still financial disparity between Hebei and the developed area, its per capita GDP has little influence on drawing investment and talents from other areas.

(2) Financial policies of the government are out-dated. Although the financial source for science and technology has increased rapidly, only a handful of small and micro enterprises are able to share it due to appropriation. Thus, the government must conduct a reform of its policies. In addition, as the separate system of performance assessment for scientific and technological finance has not been established in various financial institutions, institutions provide inadequate support in order to avoid risk. Compared with state-owned enterprises, technology-based small and micro enterprises obtain less support in such preferential policies as government guarantee, venture fund, and taxation.

(3) The ecological environment for finance in Hebei is comparatively poor. Many factors restrict the development of technology-based enterprises. The first problem is the unbalanced ecological structure for finance, including the unbalance between direct financing and indirect financing, regular finance and irregular finance, and the financial innovation and financial regulation. In addition, the financial ecology also faces deficiency of inner elements. As many technology-based enterprises are small and medium enterprises with characteristics of small credit lines and high cost, quite a few of financial institutions provide them loans due to the augment of management expenditure. In particular, the overprotection and insufficient regulation coexist in financial ecology.

(4) Credit rating and information publishing system has not been established. First, no enterprises provide service of evaluation of intangible assets like credit rating and brands and patents, thus restricting financing, especially applying for loans. Second, without unified and open information publishing platform, the dependent intermediary enterprises in Hebei obtain inadequate information. As a result, they grow slowly.

(5) Technology-based small and micro enterprises in Hebei have some weakness themselves. These enterprises are featured by small scale, limited registered capital and a few of fixed assets. They are incapable of conducting research and development of science and technology, having not yet formed the integration of production-study-research. The Hebei province has not set up the punishing system of dishonesty. The cost of dishonesty of small and micro enterprises is much lower than that of large enterprises, and they can earn more than they lose in dishonesty. Thus, many small and micro enterprises have no awareness of honesty, being opportunistic in their operation.

\section{Finance supporting models of technology-based small and micro enterprises in low-carbon economy in Hebei}

\section{1 the deficiency of financial efficiency in the low-carbon economy}

Two models are used to analyze the game between the Hebei government and enterprises and among enterprises. At first, the authors suppose that both the provincial government and technology-based small and micro enterprises are rational. And these enterprises are in pursuit of 
maximizing their profit potential. With the guidance of low-carbon economy, the provincial government has two strategic choices: providing finance supporting or not. Meanwhile, enterprises can also choose to implement the policies of low-carbon transformation, or continue its old pattern of economic development. On this occasion, the payoff matrix is shown in figure 2.

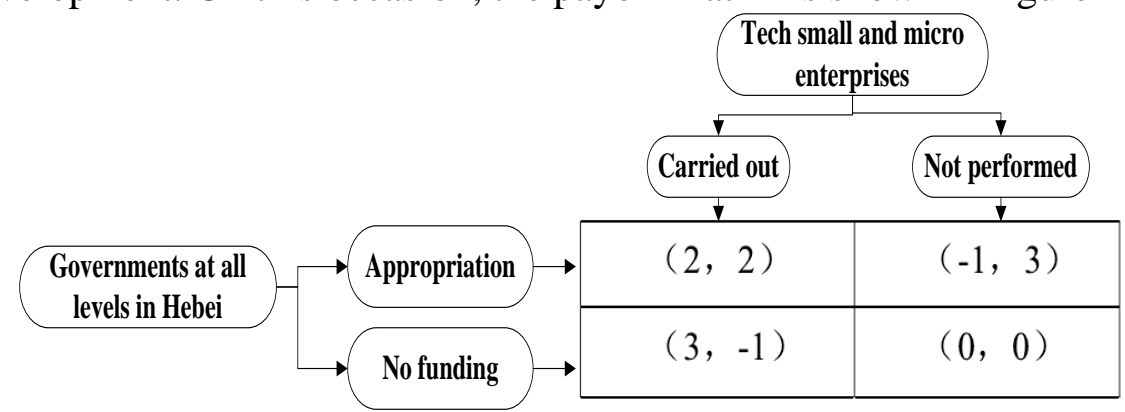

Figure 2 model: the deficiency of financial efficiency in government and enterprises in the low-carbon economy

In the game, whether the provincial government provides funding or not, the enterprises will obtain more profit by not performing the low-carbon policy. Thus, the optimal ways for enterprises and government are respectively not performing the policy and not providing funding. This is the Nash Equilibrium in the model. However, compared with providing funding and performing the policy, the total utility of the Nash Equilibrium is less. In fact, it reflects the famous prisoner's dilemma in the game theory.

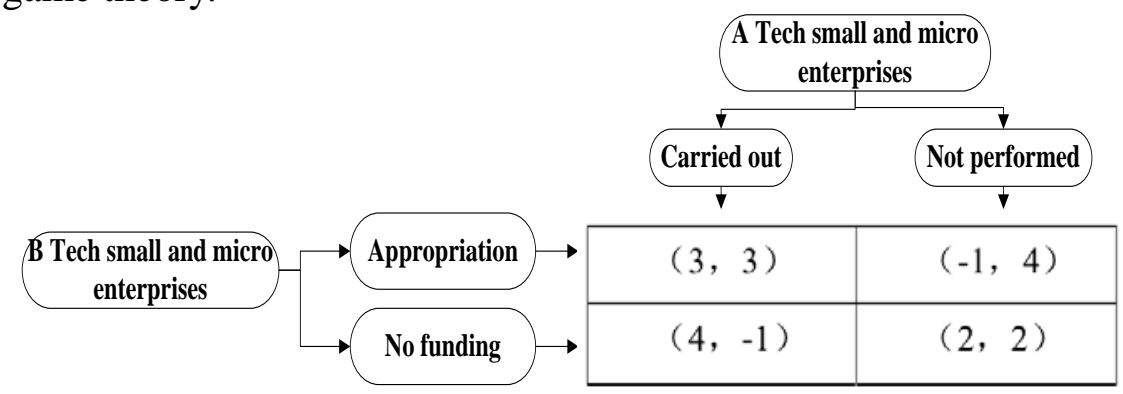

Figure 3 model: the deficiency of financial efficiency among enterprises in the low-carbon economy

We suppose two rational game-agents: company A and B. In the context of the low-carbon economy, both A and B have the choices of performing the low-carbon policy or not, as showed in figure 3. In this game, Whether A performs the policy or not, B will gain more utility by not performing the policy. As a result, not performing the policy is the optimal method for both A and B. This is also the Nash Equilibrium which by no means induces most utility. In both the two models, the individual's optimal choice gives rise to the non-optimal choice in the group, and the maximization of individual's interests affects that of the group.

\subsection{The model based on allocation of financial fund}

In this model, we suppose that a) the government and enterprises are in pursuit of their individual maximal utility; b) the process represents static game of complete information; c) enterprises are myopic to some extent influenced by the transformation cost and performance examination system. We define governments at all levels in the province as $C$, enterprises as $L$, investment level in the low-carbon economy as $\mathrm{E}$, and investment level in the traditional economy as $\mathrm{L}$. So $\mathrm{E}_{\mathrm{L}}$ is the capital invested by enterprises on the development of low-carbon economy, $E_{C}$ is the finance invested on the low-carbon economy by governments at all levels in the province, $I_{L}$ means the capital invested by enterprises on the traditional economy, and $\mathrm{I}_{\mathrm{C}}$ means the finance invested on the traditional economy by government at all levels in the province. We assume $0<\alpha, \beta, \gamma<1 ; \gamma+\beta \leq 1$; $\alpha+\beta \leq 1$. The investment on the low-carbon economy may cause externality which has more influence on all governments in the province, so these governments will take much more consideration of the externality than enterprises and we assume $\alpha<\gamma$. The aim of governments and enterprises are identical: they want to maximize the payoff function on the basis of meeting their 
budget constraint. Then the problems faced by governments at all levels in the province are:

$$
\begin{aligned}
& \max _{\left\{E_{C}, I_{C}\right\}} R_{C}=\left(E_{c}+E_{L}\right)^{\gamma}\left(L_{c}+I_{L}\right)^{\beta} \\
& \text { st } \quad E_{c}+I_{C} \leq B_{C}, E_{C} \geq 0, I_{C} \geq 0 \\
& \max _{\left\{E_{C}, I_{C}\right\}} R_{L}=\left(E_{c}+E_{L}\right)^{\alpha}\left(L_{c}+I_{L}\right)^{\beta} \\
& \text { st } \quad E_{L}+I_{L} \leq B_{L}, E_{L} \geq 0, I_{L} \geq 0
\end{aligned}
$$

Resolving the first order optimal condition for the optimization problem above, we get the response functions of governments and enterprises as follows.

$$
\begin{aligned}
& E_{C}^{*}=\max \left\{\frac{\gamma}{\gamma+\beta}\left(B_{C}+B_{L}\right)-E_{L}, 0\right\} \\
& E_{L}^{*}=\max \left\{\frac{\alpha}{\alpha+\beta}\left(B_{C}+B_{L}\right)-E_{C}, 0\right\}
\end{aligned}
$$

$\mathrm{I}_{\mathrm{C}}$ and $\mathrm{I}_{\mathrm{L}}$ are cancelled according to budget constraint condition. The optimal volume of total investment expected by enterprises in the low-carbon economy is smaller than that expected by the governments.

$$
E_{L}^{*}+E_{C}=\frac{\alpha}{\alpha+\beta}\left(B_{C}+B_{L}\right) \leq \frac{\gamma}{\gamma+\beta}\left(B_{C}+B_{L}\right)=E_{L}+E_{C}^{*}
$$

For at least one party of the governments and enterprises, the optimal solution at the point of equilibrium will be the equilibrium solution. As shown in the figure 4, if $B_{C} \geq \gamma\left(B_{C}+B_{L}\right) /(\gamma+\beta)$, then the Nash Equilibrium will be:

$$
\begin{gathered}
E_{L}^{*}=0, I_{L}^{*}=B_{L} \\
E_{C}^{*}=\frac{\gamma}{\beta+\gamma}\left(B_{C}+B_{L}\right), \quad I_{C}^{*}=B_{C}-\frac{\gamma}{\beta+\gamma}\left(B_{C}+B_{L}\right)
\end{gathered}
$$

The Nash Equilibrium illustrates that enterprises invest all capitals on the traditional economy, and the governments invest the rest of finance on the traditional economy after meeting the capital need of the development of the low-carbon economy.

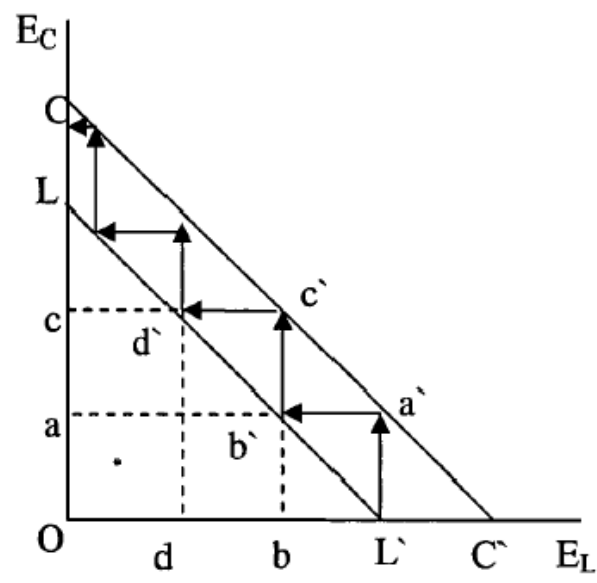

Figure 4 solving graph of equilibrium solution

Although from the perspective of the governments, the investment on the low-carbon economy is insufficient, enterprises intend to not invest on the low-carbon economy for the sake of the cost and profit of transformation. Alongside the virtuous circle in the low-carbon economy, the governments will have difficulties in meeting the preferential demand of enterprises even though they spend all budgets on the low-carbon economy. Thus, enterprises will allocate specific finance to develop the low-carbon economy.

\subsection{The model based on finance allocation monitored by the policy}

In the course of developing low-carbon economy, there is a game between the central 
government and the local government in implementing and regulating policies. This paper constitutes a model of game to analysis how the central and local governments choose and conduct their strategic. We assume that 1 ) the government and the enterprise are both rational, with the aim of maximizing their utility; 2) information spreads in a full and complete way, and every party is able to get the collection of the other's payoff function and strategic space. The enterprise can choose to implement the policy or refuse to do so, while the government may choose to supervise the enterprise or otherwise. When the enterprise implements the policy, it brings utility "a" to the government, and the government has to spend " $\mathrm{b}$ ". If the enterprise is found to negatively implement the policy, the government will fine it "F". We consider the cost of the supervision is not more than the utility and fine income from the enterprise, so the government will be able to supervise the enterprise actively. That is $\mathrm{C}<\mathrm{a}+\mathrm{F}$. The payoff matrix of the game is shown in figure 5.

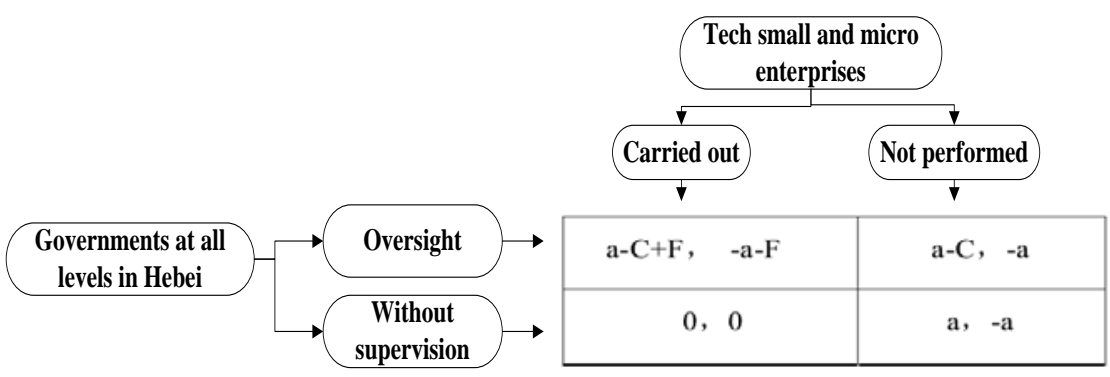

Figure 5 the payoff matrix of the game

The probability of the government supervising is $\mu$, and the probability of negatively implementing the policy is $\varepsilon$. In terms of the givene, the expected revenue of supervising $(\mu=1)$ and not supervising $(\mu=0)$ respectively are :

$$
\begin{aligned}
& R_{C}(1, \varepsilon)=(a-c+F) \varepsilon+(a-C)(1-\varepsilon)=\varepsilon F+a-c \\
& R_{C}(0, \varepsilon)=0 \varepsilon+a(1-\varepsilon)=a(1-\varepsilon)
\end{aligned}
$$

The solution of $\mathrm{R}_{\mathrm{C}}(1, \varepsilon)=\mathrm{R}_{\mathrm{C}}(0, \varepsilon)$ is $\varepsilon^{*}=\mathrm{C} /(\mathrm{a}+\mathrm{F})$.

It shows that a) when the probability of negatively implementing the policy is less than $C /(a+F)$, not supervising is the optimal choice for the government; b) when the probability of negatively implementing the policy is more than $\mathrm{C} /(\mathrm{a}+\mathrm{F})$, supervising is the optimal choice; $c)$ when the probability of negatively implementing the policy is equal to $C /(a+F)$, the government will supervise the enterprise randomly. In terms of the given $\mu$, the expected revenue of supervising and not supervising respectively are :

$$
\begin{aligned}
& R_{L}(u, 1)=-(a+F) u+0(1-u)=-(a+F) u \\
& R_{L}(u, 0)=-a u+(-a)(1-u)=-a
\end{aligned}
$$

The solution of $\mathrm{R}_{\mathrm{L}}(\mu, 1)=\mathrm{R}_{\mathrm{L}}(\mu, 0)$ is $\mu^{*}=\mathrm{a} /(\mathrm{a}+\mathrm{F})$.

It shows that) if the probability of the government supervising is less than a $/(a+F)$, not implementing or negatively implementing will be the optimal choice; b) if the probability of the government supervising is more than a / $(\mathrm{a}+\mathrm{F})$, actively implementing the policy will be the optimal choice; c) if the probability of the government supervising is equal to a /(a+F), the enterprise will implement the policy randomly. Thus, the government should actively improve its system of supervision and reduce the cost. Then, the government should show its preference and resolution in developing the low-carbon economy so as to increase the dependence of the macro economy on the low-carbon economy. Finally, strict punishment should be given to those enterprises which not implement or negatively implement the low-carbon policy.

\section{Suggestion on finance supporting of technology-based small and micro enterprises}

The government should make clear of the property right of carbon emission and push the carbon emission trading. The essence of the market of carbon emission trading is recognition of the 
commercialization of carbon assets. The carbon emission space is of quantification, capitalization and marketization in the market. It is a kind of resource consuming enormous energy and materials in the process of production, instead of a non-public matter. The government should reduce the carbon emission through effectively allocating the property right of carbon emission in the market. Laws and regulations should be improved to establish the specialized trading platform of carbon emission. Meanwhile, the government should play a full role in the trading so as to further enhance the monitor of emission source and the market. The market system of carbon trading should be promoted as soon as possible to advance the low-carbon economy.

The government should drive scientific and technical innovation and lead the development of low-carbon economy. In order to reduce the $\mathrm{CO} 2$ emission, and maximize the energy utilization rate and resource production rate, the government should break through in such aspects as the theory, method and evaluation system. In the rural areas, the government should advocate farmers to use few pesticides and chemical fertilizer, and popularize solar power collectors and biogas technology. Technology of energy saving and emission reduction should be used to increase the overall efficiency of energy sources and gradually eliminate the excessive dependence of the traditional industry on high-carbon industries. The high- carbon industries should be gradually restricted, and the high-carbon products should be obsoleted day by day. The government should work out to monitor the high- carbon industries, appropriately increase the tax, while formulate preferential policies to encourage the development of the low-carbon industries. The government should also arouse people's awareness of environmental protection and low-carbon life, advocate low-carbon and energy-consuming behaviors as well as increase people's attention and sense of duty on the low-carbon economy.

The government should strengthen support on laws and policies and enhance supervision. The award and tax policy should be improved. For example, the government should give preferential tax policy to those enterprises which anticipate the research and development of carbon capture and sequestration. Giving the award of low tax rate, reduction and exemption of tax to enterprises which engage in technological innovation and low-carbon operation. Meanwhile, those energy-consuming enterprises with serious pollution and low resource utilization rate should face high tax rate or punishment. The central government should enhance its authority of supervision and promote the responsibility system of low-carbon target in local governments. Supervision and punishment should be enhanced to ensure the policies are effectively performed, and the low-carbon finance is used in the place where it is needed most. The finance should be used in the most appropriate way.

\section{Conclusions}

The emergence and development of technology-based small and micro enterprises are not only a symbol of scientific and technical progress, but also an inevitable tendency of social advance. Although technology-based small and micro enterprises have the most potential, they still have some problems such as capital deficiency, low market competitiveness and small scale. Compared with large and medium enterprises, they represent vulnerable. On account of this, this paper constitutes the finance supporting model of technology-based small and micro enterprises in the low-carbon economy in Hebei, in the aim of accelerating the development of technology-based small and micro enterprises in a healthy, fair and harmonious environment and upgrading the national system of innovation.

\section{Acknowledgements}

The research work was supported by Hebei Province Department of Science and Technology under Grant No. 15457636D

\section{References}

[1] Zhijiang Tang, Hui Miao and Haishen Li. Study on Finance Support of the Development of 
Technology-Based Small and Micro Enterprises [J]. ZHEJIANG FINANCE, 2010(8).

[2] Hui Miao, Haishen Li. Problems and Measures of Financing of Technology-Based Small and Micro Enterprises [J]. CAIKUAI YUEKAN, 2010(6).

[3] Zhijiang Tang, Hui Miao, Haishen Li. New Pressure Faced by Small and Medium Enterprises on Financing and Strategic Innovation of Banking [J]. CREDIT REFERENCE, 2012(1).

[4] Haishen Li. Study on Finance Support of Self-dependent Innovation in Hebei [J]. SCIENCE \& TECHNOLOGY INFORMATION, 2009(5).

[5] Junfeng Wang, Yan Wang. Study on Problems of the Development of Small and Micro Enterprises [J]. COMMERCIAL RESEARCH, 2012(86): 87-89.

[6] Huilian Li, Shunji Guo, Donghui Kong. Report on the Existence of Small and Micro Enterprises [N]. CHINA ECONOMIC TIMES, 2012-06027 (10).

[7] Feng Qiu. Analysis on Supporting Effect of Structure Tax Reduction of Small and Micro Enterprises [J]. QINGHAI FINANCE, 2012(4):35-37.

[8] Sucong Duan. Study on Tax Policies Advancing Small and Micro Enterprises [J]. CHINESE \& FOREIGN ENTREPRENEURS, 2012(11): 97-99.

[9] Chao Cui. Study on Policies of Finance and Tax Promoting the Environment of Small and Micro Enterprises [J]. CHINA STATE FINANCE, 2012(2): 46-47.

[10] Yun Tian. Study on Policies of Chinese Small and Micro Enterprises in Post-crisis Era [J]. ECONOMIC RESEARCH GUIDE, 2012(22): 30-32. 